Original Article

\title{
Effects of fast expiration exercises without pressure on the respiratory muscle strength of healthy subjects
}

\author{
Hiroshi Ishida, PhD ${ }^{1)^{*}}$, Yuri Kuramoto, PTS ${ }^{1)}$, Daiki Ikeda, PTS ${ }^{1)}$, Susumu Watanabe, PhD ${ }^{1)}$ \\ 1) Department of Rehabilitation, Faculty of Health Science and Technology, Kawasaki University of \\ Medical Welfare: 288 Matsushima, Kurashiki, Okayama 701-0193, Japan
}

\begin{abstract}
Purpose] The aim of this investigation was to determine the effects of 4 weeks of fast expiration exercises performed without pressure on respiratory muscle strength. [Subjects and Methods] Respiratory muscle strength of the training group that performed fast expiration exercises $(\mathrm{n}=12)$ was compared with that of a control group that performed no exercises $(\mathrm{n}=12)$. The fast expiration exercises were performed using a peak expiratory flow meter device and consisted of 20 fast expiration exercises performed 3 times per week for 4 weeks. Maximal expiratory and inspiratory pressures were evaluated as respiratory muscle strength using a spirometer pre- and postintervention. [Results] There were significant increases in maximal expiratory pressure from $76.9 \pm 29.1$ to $96.1 \pm$ $37.5 \mathrm{cmH}_{2} \mathrm{O}$ and maximal inspiratory pressure from $80.8 \pm 36.6$ to $95.3 \pm 37.6 \mathrm{cmH}_{2} \mathrm{O}$ in the training group, but there was no significant difference in respiratory muscle strength between pre- and post-intervention in the control group. [Conclusion] Fast expiration exercises may be beneficial for increasing respiratory muscle strength. The findings of this study should be considered when prescribing a variation of the expiratory muscle strength training, as part of a pulmonary rehabilitation program.

Key words: Expiratory muscle strength training, Maximal expiratory pressure, Maximal inspiratory pressure
\end{abstract}

(This article was submitted Apr. 19, 2016, and was accepted Jun. 9, 2016)

\section{INTRODUCTION}

Cough serves as an important airway defense mechanism. The effectiveness of cough is dependent on the capacity of the respiratory muscles to increase intrathoracic pressure which generates the requisite cough expiratory flows and airstream velocities $^{1)}$. The contraction of the expiratory muscles increases the intrathoracic pressure, diminishes lung volume, and facilitates expiratory flow. For cough to be effective, the flow caused by the expiratory muscles should be high.

Expiratory muscle strength training (EMST) programs are known to increase the force output of expiratory muscles ${ }^{2)}$. In general, EMST performed using pressure threshold devices strengthens the expiratory muscles by increasing the expiratory load during breathing exercises ${ }^{3-23}$. The mechanism that creates the expiratory load in pressure threshold devices is a spring-loaded relief valve housed inside the device. The valve blocks the flow of air until sufficient expiratory pressure is produced; then the valve opens, and air begins to flow through the device. The physiologic load on the expiratory muscles can be increased or decreased depending on the device setting. Overload, the basis of strength training, can be accomplished with pressure threshold devices. A few previous studies have described how to blow during EMST ${ }^{11,16,20)}$. In these previous studies, subjects were instructed to exhale as hard as possible using a pressure threshold devices ${ }^{11)}$, to breathe rapidly with maximal effort ${ }^{16)}$, and to blow as forcefully as possible ${ }^{20}$. If motor units are activated in a task-specific manner, the expiratory muscle activity will differ with the task. However, little is known about the effects of the expiratory flow speed during EMST. Our aim was to study the effects of 4 weeks of fast expiration (FE) exercises performed without a pressure threshold on respiratory muscle strength.

\footnotetext{
*Corresponding author. Hiroshi Ishida (E-mail: ishida@mw.kawasaki-m.ac.jp)

(C)2016 The Society of Physical Therapy Science. Published by IPEC Inc.

This is an open-access article distributed under the terms of the Creative Commons Attribution Non-Commercial No Derivatives (by-nc-nd) License $<$ http://creativecommons.org/licenses/by-nc-nd/4.0/>.
} 


\section{SUBJECTS AND METHODS}

Twenty-six healthy volunteers participated in this trial. The subjects were physiotherapy students attending the Kawasaki University of Medical Welfare. The protocol for the present study was approved by the Ethics Committee of the Kawasaki University of Medical Welfare. Written informed consent was obtained and the rights of the subjects were protected. Subjects were excluded if they presented with a history of chronic or acute cardiac, pulmonary, or neuromuscular disease, had a history of smoking, or had an acute upper respiratory infection; none of the subjects had participated in a sports activity for more than 3 hours a week in the past year. All of the subjects' pulmonary function measures of percentage of the predicted vital capacity (\%VC: vital capacity/predicted vital capacity) and the forced expiratory volume in one second (\% $\mathrm{FEV}_{1}$ : forced expiratory volume in one second/forced vital capacity). The values were calculated from measurements made by a multi-functional spirometer (HI-801; Chest Co., Ltd., Tokyo, Japan) and were within the normal range. All the subjects were asked to report any significant changes in their levels of physical activity during their participation in the study.

This study was a prospective cohort study. Measurements of respiratory muscle strength were performed before and after a 4-week intervention. The subjects were randomly assigned to the training $(n=14)$ and control groups $(n=12)$. Practice measurements were performed on all subjects on the day before the baseline in order to avoid possible training and learning effects.

Maximal expiratory and inspiratory pressures $\left(\mathrm{PE}_{\max }\right.$ and $\left.\mathrm{PI}_{\max }\right)$ at the mouth are most commonly used as noninvasive measurements of respiratory muscle strength ${ }^{3-23)}$. $\mathrm{PE}_{\max }$ and $\mathrm{PI}_{\max }$ were measured three times using a multi-functional spirometer with an optional respiratory pressure unit. Pulmonary function and respiratory muscle strength were measured using the same spirometer. Subjects sat and wore nose clips during the measurements. $\mathrm{PE}_{\max }$ was measured using expiration from total lung capacity. For measurement of $\mathrm{PE}_{\max }$, the subjects were instructed to inspire fully to total lung capacity, and then to forcefully exhale against an occluded mouthpiece for $3 \mathrm{~s}$. $\mathrm{PI}_{\max }$ was measured from the residual volume. For measuring $\mathrm{PI}_{\max }$, the investigator instructed the subjects to exhale fully to residual volume, then to forcefully inspire against an occluded mouthpiece for $3 \mathrm{~s}$. One-minute rests were taken between the measurements. All the data were collected by the same investigator. The maximum value of the three trials was used in the analysis. Percent changes from pre-intervention respiratory muscle strength were calculated as [(post - pre $) /$ pre respiratory muscle strength $\times 100](\%)$.

The FE exercises were performed using a peak expiratory flow meter device (Assess, Full range; Philips Respironics G.K., Tokyo, Japan) for feedback of the performance, and consisted of 20 FE exercises at the subject's own pace to avoid "hard" effort, equivalent to a rating of 15 on the Borg scale ${ }^{24)}$. The time duration required for completion of the $20 \mathrm{FE}$ exercises was 3 minutes. The breath that subjects blew into a mouthpiece of the device exited from an opening on the opposite side of the mouthpiece and another vent which was located above an internal piston. The piston moved against a spring during expiration and moved the needle, avoiding the creation of expiratory load. The training was performed 3 times a week for 1 month under the supervision of an investigator. During training, the investigator instructed the subjects to inspire fully to total lung capacity, and then to blow through the mouthpiece as fast as possible. The subjects were told to pay attention to the speed of instantaneous expiration not the volume, and the investigator also instructed that it was not necessary to exhale to residual volume.

SPSS Statistics 23.0 was used for the statistical analysis. Differences in baseline characteristics of the subjects and respiratory muscle strengths between the groups were analyzed using the unpaired t-test. Differences in respiratory muscle strength between pre- and post-intervantion were analyzed using the paired t-test. Values were considered statistically significant at values of $\mathrm{p}<0.05$.

\section{RESULTS}

Two subjects of the training group withdrew from the study because they had an acute upper respiratory infection during the intervention period. Therefore, the results of the remaining 24 subjects were analyzed.

There were no significant differences between the two groups in terms of age, height, weight, $\% \mathrm{VC}$, and $\% \mathrm{FEV}_{1}$ at the beginning of the study (Table 1).

Before the trial period, there were no differences in $\mathrm{PE}_{\max }$ or $\mathrm{PI}_{\max }$ between the two groups. At the end of intervention, a significant increase in the $\mathrm{PE}_{\max }$ and $\mathrm{PI}_{\max }$ was found in the training group, but not in the control group (Table 2).

\section{DISCUSSION}

To our knowledge, this is the first study to show the effects of 4 weeks of FE exercises without pressure on the respiratory muscle strength of healthy subjects. As both $\mathrm{VC}$ and $\mathrm{FEV}_{1}$ were within the normal range, the subjects had normal pulmonary function. The results of this study show that there were significant increases in $\mathrm{PE}_{\max }$ and $\mathrm{PI}_{\max }$ at the end of the intervention period in the training group. These results indicate the efficacy of FE exercises in increasing the respiratory muscle strength of healthy individuals.

The increase in $\mathrm{PE}_{\max }$ between pre- and post-intervention was $30 \%$ in the training group. This reflects an increase in 
Table 1. Characteristics of the subjects

\begin{tabular}{lcc}
\hline \multirow{2}{*}{ Characteristics } & Training group & Control group \\
\cline { 2 - 3 } & $(\mathrm{n}=12)$ & $(\mathrm{n}=12)$ \\
\hline Age (years) & $20.5 \pm 0.7$ & $20.7 \pm 0.5$ \\
Male/Female (n) & $6 / 6$ & $6 / 6$ \\
Height $(\mathrm{cm})$ & $161.6 \pm 7.6$ & $165.6 \pm 10.1$ \\
Weight $(\mathrm{kg})$ & $54.9 \pm 10.5$ & $54.3 \pm 7.5$ \\
$\% \mathrm{VC}$ & $102.5 \pm 12.9$ & $104.1 \pm 12.8$ \\
$\% \mathrm{FEV}$ & $97.2 \pm 16.8$ & $98.7 \pm 8.8$ \\
\hline
\end{tabular}

$\% \mathrm{VC}$ : vital capacity/predicted vital capacity. $\% \mathrm{FEV}_{1}$ : forced expiratory volume in one second/forced vital capacity

Table 2. Mean \pm standard deviation of respiratory muscle strength and percent change

\begin{tabular}{clccc}
\hline & & Pre $\left(\mathrm{cmH}_{2} \mathrm{O}\right)$ & Post $\left(\mathrm{cmH}_{2} \mathrm{O}\right)$ & Percent change $(\%)$ \\
\hline \multirow{2}{*}{ Training group } & $\mathrm{PE}_{\max }$ & $76.9 \pm 29.1$ & $96.1 \pm 37.5 *$ & $30.0 \pm 38.4$ \\
& $\mathrm{PI}_{\max }$ & $80.8 \pm 36.6$ & $95.3 \pm 37.6 *$ & $23.9 \pm 29.7$ \\
\multirow{2}{*}{ Control group } & $\mathrm{PE}_{\max }$ & $68.1 \pm 18.3$ & $74.1 \pm 19.9$ & $10.8 \pm 19.6$ \\
& $\mathrm{PI}_{\max }$ & $77.6 \pm 31.7$ & $79.5 \pm 31.5$ & $4.9 \pm 15.8$ \\
\hline
\end{tabular}

$* \mathrm{p}<0.05 . \mathrm{PE}_{\max }:$ maximal expiratory pressure, $\mathrm{PI}_{\max }:$ maximal inspiratory pressure

expiratory force generating capacity and is comparable to previously reported $\mathrm{PE}_{\max }$ increases of $27-41 \%$ in healthy young adults participating in a 4 -week EMST program using pressure threshold devices ${ }^{11,22)}$. These previous studies used the protocol of 5 cycles of 5 expirations through pressure threshold devices, with $75 \%$ of $\mathrm{PE}_{\max }{ }^{11,22)}$. Baker et al. ${ }^{11)}$ studied the effects of a training frequency of 5 days per week after 4- and 8-week training periods. Anand et al. ${ }^{22}$ ) reported the effects of training frequencies of 3 and 5 days per week after a 4-week training period. The major finding of this study was that $20 \mathrm{FE}$ exercises performed for 3 days per week in a 4-week intervention without expiratory pressure strengthened the expiratory muscles with an effect comparable to EMST which expiratory load.

The training period used in many previous EMST studies was 4 weeks ${ }^{3,11,16,18-22)}$. A limb strength training study that demonstrated a significant improvement in strength within 4 weeks indicated that the primary mechanisms influencing muscle strength change during the first 4 weeks of training are neural adaptations ${ }^{25}$, 26). It is possible that strength training causes changes within the nervous system that allow a trainee to more fully activate prime movers in specific movements, and to better coordinate the activation of all relevant muscles; therefore, changes within the nervous system may allow force to be developed more rapidly ${ }^{26}$. These neural adaptations occur as a result of the ability of the central nervous system to respond to changes in functional demands. Hence, in this study, the primary mechanism that influenced a respiratory muscle strength change during the 4 weeks of training may have been neural adaptation. Beyond 4 weeks of training, there is evidence that other mechanisms, such as peripheral or structural changes, may be responsible for improvements in strength. Further studies are necessary to clarify the effects of longer periods of FE exercises.

A few previous studies have indicated that EMST significantly increases inspiratory muscle strength ${ }^{6,8)}$, but other studies have reported no significant increase in inspiratory muscle strength after EMST ${ }^{13}{ }^{16}$. In this study, FE exercises significantly increased not only expiratory but also inspiratory muscle strength. Increases in activity of the expiratory muscles may expand the diaphragm at residual volume, and improve the length-tension characteristics for generation of pressure required to produce a subsequent inspiration ${ }^{27,28)}$. Our results indicate that FE exercises could increase both expiratory and inspiratory muscle strength. However, there is ambiguity over whether the expiratory muscle activity increased while measuring respiratory muscle strength, because the expiratory muscle activity was not measured in the present study.

The present study had some limitations. First, the sample size was small. Second, all the subjects were healthy young adults. Further studies, using larger and broader samples of asymptomatic individuals with weakness of respiratory muscle strength (e.g. spinal cord injury, chronic obstructive pulmonary disease, multiple sclerosis, amyotrophic lateral sclerosis, and Parkison's disease) are needed to determine whether FE exercises increase respiratory muscle strength. Third, a direct comparison of the effects on the respiratory muscle strength between a group performing FE exercises without pressure and a group performing general EMST using a pressure threshold device was not performed. Accordingly, the effects of FE exercises in combination with a pressure threshold device should be quantified. Finally, the evaluation of the effect was limited to respiratory muscle strength. Influences of the exercise on pulmonary function, exercise capability, and feeling of breathing effort during exercise should also be investigated.

Our results indicate that $20 \mathrm{FE}$ exercises, performed for 3 days per week in a 4-week intervention using a peak flow meter 
without a threshold pressure load, strengthened not only expiratory but also inspiratory muscle strength. Thus, FE exercises may be beneficial for respiratory muscle strength. The findings of this study should be considered when prescribing a variation of the EMST as part of a pulmonary rehabilitation program.

\section{ACKNOWLEDGEMENTS}

This work was supported by JSPS KAKENHI Grant Number 15K16383. The authors wish to thank the subjects for their invaluable contribution to this study.

\section{REFERENCES}

1) McCool FD: Global physiology and pathophysiology of cough: ACCP evidence-based clinical practice guidelines. Chest, 2006, 129: 48S-53S. [Medline] [CrossRef]

2) Sapienza CM, Wheeler K: Respiratory muscle strength training: functional outcomes versus plasticity. Semin Speech Lang, 2006, 27: 236-244. [Medline] [CrossRef]

3) Suzuki S, Sato M, Okubo T: Expiratory muscle training and sensation of respiratory effort during exercise in normal subjects. Thorax, 1995, 50: $366-370$. [Medline] [CrossRef]

4) Smeltzer SC, Lavietes MH, Cook SD: Expiratory training in multiple sclerosis. Arch Phys Med Rehabil, 1996, 77: 909-912. [Medline] [CrossRef]

5) Gosselink R, Kovacs L, Ketelaer P, et al.: Respiratory muscle weakness and respiratory muscle training in severely disabled multiple sclerosis patients. Arch Phys Med Rehabil, 2000, 81: 747-751. [Medline] [CrossRef]

6) Akiyoshi H, Takahashi H, Sugawara K, et al.: The effect of expiratory muscle training on respiratory strength. Rigaku Ryohogaku, 2001, 28: 47-52 (in Japanese).

7) Sapienza CM, Davenport PW, Martin AD: Expiratory muscle training increases pressure support in high school band students. J Voice, 2002 , 16: 495-501. [Medline] [CrossRef]

8) Sato M, Satake M, Shioya T, et al.: The study on effective load pressure for the respiratory muscle training. Rigaku Ryohogaku, 2002, 29: 37-42 (in Japanese).

9) Weiner P, Magadle R, Beckerman M, et al.: Specific expiratory muscle training in COPD. Chest, 2003, 124: 468-473. [Medline] [CrossRef]

10) Weiner P, Magadle R, Beckerman M, et al.: Comparison of specific expiratory, inspiratory, and combined muscle training programs in COPD. Chest, 2003, 124: 1357-1364. [Medline] [CrossRef]

11) Baker S, Davenport P, Sapienza C: Examination of strength training and detraining effects in expiratory muscles. J Speech Lang Hear Res, 2005, 48: $1325-$ 1333. [Medline] [CrossRef]

12) Saleem AF, Sapienza CM, Okun MS: Respiratory muscle strength training: treatment and response duration in a patient with early idiopathic Parkinson's disease. NeuroRehabilitation, 2005, 20: 323-333. [Medline]

13) Sasaki M, Kurosawa H, Kohzuki M: Effects of inspiratory and expiratory muscle training in normal subjects. J Jpn Phys Ther Assoc, 2005, 8: 29-37. [Medline] [CrossRef]

14) Chiara T, Martin AD, Davenport PW, et al.: Expiratory muscle strength training in persons with multiple sclerosis having mild to moderate disability: effect on maximal expiratory pressure, pulmonary function, and maximal voluntary cough. Arch Phys Med Rehabil, 2006, 87: 468-473. [Medline] [CrossRef]

15) Chiara T, Martin D, Sapienza C: Expiratory muscle strength training: speech production outcomes in patients with multiple sclerosis. Neurorehabil Neural Repair, 2007, 21: 239-249. [Medline] [CrossRef]

16) Griffiths LA, McConnell AK: The influence of inspiratory and expiratory muscle training upon rowing performance. Eur J Appl Physiol, $2007,99: 457-466$. [Medline] [CrossRef]

17) Mota S, Güell R, Barreiro E, et al.: Clinical outcomes of expiratory muscle training in severe COPD patients. Respir Med, 2007, 101: 516-524. [Medline] [CrossRef]

18) Sasaki M: The effect of expiratory muscle training on pulmonary function in normal subjects. J Phys Ther Sci, 2007, 19: 197-203. [CrossRef]

19) Wingate JM, Brown WS, Shrivastav R, et al.: Treatment outcomes for professional voice users. J Voice, 2007, 21: 433-449. [Medline] [CrossRef]

20) Kim J, Davenport P, Sapienza C: Effect of expiratory muscle strength training on elderly cough function. Arch Gerontol Geriatr, 2009, 48: 361-366. [Medline] [CrossRef]

21) Pitts T, Bolser D, Rosenbek J, et al.: Impact of expiratory muscle strength training on voluntary cough and swallow function in Parkinson disease. Chest, 2009, 135: 1301-1308. [Medline] [CrossRef]

22) Anand S, El-Bashiti N, Sapienza C: Effect of training frequency on maximum expiratory pressure. Am J Speech Lang Pathol, 2012, 21: 380-386. [Medline] [CrossRef]

23) Westerdahl E, Wittrin A, Kånåhols M, et al.: Deep breathing exercises with positive expiratory pressure in patients with multiple sclerosis—a randomized controlled trial. Clin Respir J, 2015. [Medline] [CrossRef]

24) Borg GA: Psychophysical bases of perceived exertion. Med Sci Sports Exerc, 1982, 14: 377-381. [Medline] [CrossRef]

25) Moritani T, deVries HA: Neural factors versus hypertrophy in the time course of muscle strength gain. Am J Phys Med, 1979, 58: 115-130. [Medline]

26) Sale DG: Neural adaptation to resistance training. Med Sci Sports Exerc, 1988, 20: S135-S145. [Medline] [CrossRef]

27) Grimby G, Goldman M, Mead J: Respiratory muscle action inferred from rib cage and abdominal V-P partitioning. J Appl Physiol, 1976, 41: 739-751. [Medline]

28) Goldman MD, Grassino A, Mead J, et al.: Mechanics of the human diaphragm during voluntary contraction: dynamics. J Appl Physiol, 1978, 44 : 840-848. [Medline] 